\title{
Chapter 3 \\ Design Science and Design Research: The Significance of a Subject-Specific Research Approach
}

\author{
Marcus Nührenbörger, Bettina Rösken-Winter, Michael Link, \\ Susanne Prediger and Anna Susanne Steinweg
}

\begin{abstract}
Considering mathematics education as a DESIGN SCIENCE has strong roots in Germany. E. Ch. Wittmann in particular contributed to the establishment of this approach. From a DESIGN SCIENCE perspective, substantial learning environments play a crucial role. They comprise mathematical tasks which are connected in an operative way, indicative of a specific epistemological structure. In such substantial learning environments, students are actively immersed in learning mathematics, and the learning environments allow for the pursuit of individual and differentiated learning processes. In this chapter, we first address the scope of Design Science and pay attention to characteristics of the learning environments and how teaching experiments can be conducted. We then focus on key ideas and their role as a design principle. In the next section, we provide a comprehensive example of designing a learning environment. Lastly, we shift our attention to the Design Research approach, which complements designing substantial learning environments by empirically studying the initiated learning processes to gain evidence for both theoretical considerations and design principles.
\end{abstract}

Keywords Design science $\cdot$ Learning environments $\cdot$ Teaching experiments • Learning processes $\cdot$ Key ideas

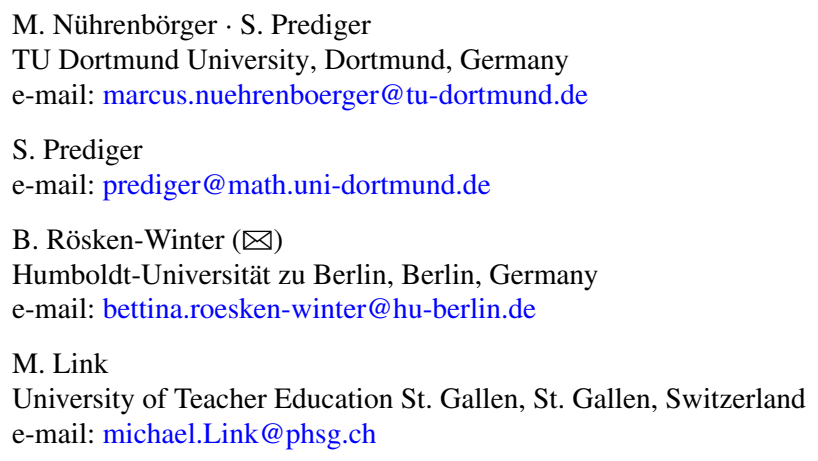

\section{A. S. Steinweg}

University of Bamberg, Bamberg, Germany

e-mail: anna.steinweg@uni-bamberg.de 


\subsection{Introduction}

DESIGN SCIENCE is a research approach with strong roots in Germany. This applies specifically for the research approach advocated in Dortmund by Wittmann and Müller (1990), assigning a central role to so-called substantial learning environments. Particularly, Wittmann (1995) outlined how these can be a starting point to establish mathematics education as a scientific field in its own right. That is, exploring the epistemological structure reflected in such learning environments or reflecting didactical principles while testing the learning environments in practice adds to a deeper understanding of both the mathematics involved and students' learning processes. Of course, there have been similar trends in Germany. Some researchers, for instance, focused on specifying and fostering 'Grundvorstellungen' ('basic ideas', see Chap. 1) and informal proving (Kirsch 1978; Blum and Kirsch 1991) or cognitive aspects of mathematical learning environments (Cohors-Fresenborg 1993). These various approaches share the responsibility for designing learning environments, testing them in practice and drawing consequences for a partial redesign. All kept a strong emphasis on the mathematical learning content rather than on generic pedagogical issues only, and all contributed to elaborating 'design principles', serving as a theoretical background for a research-based design.

In this chapter, we present the traditional 'Dortmund approach' of DESIGN SCIENCE with its focus on substantial learning environments as well as more recent developments towards Design Research.

First, Marcus Nührenbörger and Bettina Rösken-Winter discuss how the theoretical orientations of DESIGN SCIENCE are reflected in Wittmann's work, especially in the DESIGN SCIENCE project, 'mathe 2000'. By doing so, they focus on developments that are close to Wittmann's approach and have led to modifications in terms of research approaches containing collaborative and iterative designs or designing learning environments along with developing theories (Sect. 3.2). In the following contribution (Sect. 3.3), Anna Susanne Steinweg points out key ideas as a framework for designing substantial learning environments in relation to a spiral curriculum. The key ideas serve as design principles as well as guiding principles for classroom interaction. In Sect. 3.4, Michael Link presents an example of designing and examining a substantial learning environment ("number patterns in operative structured sequences of addition in grade 3"). After outlining different stages of developing such substantial learning environments, we discuss the resulting products (learning activities for students). This project already marks a partial shift as it combines elements of DESIGN SCIENCE, the original approach pursued by Wittmann, and design research, having a greater orientation towards empirically substantiating the initiated learning processes. Finally, in the last Sect. 3.5 Susanne Prediger reports on current strands of developing DESIGN SCIENCE into approaches of Design Research, with their stronger emphasis on empirical investigations. Design Research aims explicitly at gaining deep insights into teaching-learning processes, and local theories underpinning the observed learning processes, for classrooms as well as for professionalization and scaling up processes. 


\subsection{Scope of Design Science: Learning Environments and Teaching Experiments}

Advocating 'mathematics education as a DESIGN SCIENCE', E. Ch. Wittmann elaborated on constructing and investigating learning environments. From their very nature, such learning environments contain substantial mathematical contents. These allow, on the one hand, for the exploration of the epistemological structure in depth, and on the other hand, the reflection of didactical principles while testing substantial learning environments in practice, which adds to a deeper understanding of both the mathematics involved and students' learning processes. Thus, for Wittmann "the design of substantial learning environments around long-term curricular strands should be placed at the very center of mathematics education. Research, development and teacher education should be consciously related to them in a systematic way" (Wittmann 2001a, p. 4). Respectively, mathematics education has been conceptualized as a constructive scientific discipline that has contributed teaching concepts, units, examples, and materials. The main objective has been to develop feasible designs for conceptual and practical innovations, involving the teachers actively in any design process. In the following sections, we briefly explore the roots of DESIGN SCIENCE (Sect. 3.2.1), elaborate on the role of substantial learning environments (Sect. 3.2.2), and finally pay attention to the design of teaching experiments (Sect. 3.2.3). For a more detailed discussion of DESIGN SCIENCE and its relation to other European strands in mathematics education, we refer to Akinwunmi et al. (2016).

\subsubsection{Roots of DESIGN SCIENCE}

The fundamental scope of mathematics education has been the initiation and support of the deep mathematical learning processes of students. Therefore, one important research approach is aimed at designing learning environments, exploring the induced learning processes, and deriving fundamental design principles. In the Germanspeaking tradition, the notion of DESIGN SCIENCE is closely connected with Wittmann (1995), who has emphasized and elaborated this research approach over the past decades. The careful analysis of the mathematical substance and the potentials of mathematical structures within the specific designs have played a prominent role. In this regard, the concept of DESIGN SCIENCE is embedded in the German Stoffdidaktik tradition (cf. the respective chapter in this book). Describing "the specific status and the relative autonomy of mathematics education", Wittmann (1995, p. 355) pointed out that mathematics education on the one hand differs essentially from pure mathematics, and on the other hand is not simply a conglomerate discipline of mathematics involving related sciences such as psychology, sociology, or pedagogy. Rather, this 'research approach' is characterized as an applied approach whose core task is to develop practical, constructive products of acknowledged quality for 
teaching mathematics. Thus, this core task encompasses many different components such as analysing mathematical activities and related mathematical thinking, as well as developing local theories on mathematising or problem solving, to name but a few (Wittmann 1995).

DESIGN SCIENCE, according to Wittmann (1995), deals with the artificial objects of mathematics teaching (i.e., with exercises as well as specific mathematics learning and teaching processes) and adapts these constructively with a view to further developing mathematics education. The focus on designing for teaching and learning has already been referred to in former times as, for instance, by Simon (1970) who distinguished between 'artificial sciences' and 'natural sciences' as follows:

\footnotetext{
Historically and traditionally, it has been the task of the science disciplines to teach about natural things; how they are and how they work. It has been the task of engineering schools to teach about artificial things: how to make artefacts that have desired properties and how to design. (Simon 1970, p. 55)
}

In this sense, artificial sciences develop and study artificial objects that are in principle adaptable and can be changed with reference to specific objectives or functions. In 2005, Lesh and Sriraman still called for re-conceptualizing "the field of mathematics education research as that of a design science akin to engineering and other emerging interdisciplinary fields which involve the interaction of 'subjects', conceptual systems, and technology influenced by social constraints and affordances" (p. 490). However, optimising how mathematics is taught in the classroom and developing practical aids for teachers has been pursued by researchers over the past decades, employing design research with different foci (Gravemeijer and Cobb 2006; Lesh and Sriraman 2005; Hußmann and Prediger 2016; Ruthven et al. 2009; van den Akker et al. 2006).

\subsubsection{Characteristics of Substantial Learning Environments}

Wittmann and Müller (1990) concentrated their design efforts on what they called substantial learning environments, as this focus allows different aspects of several disciplines (like psychology, sociology or pedagogy) relevant for teaching and learning mathematics to be integrated (Wittmann 1995). From their perspective, students' learning is an active process, assigning particular relevance to pedagogical theories and methods of social learning.

The term 'substantial learning environment' refers to mathematical tasks which are connected in an operative way. That is, a focus on mathematical structures sets the frame for students to learn mathematics in an active and cooperative way. Therefore, the tasks are adapted to the level of learners' thinking and offer different learning ways for the students. In this sense, learning environments are open for individual and differentiated learning processes. The inherent structures of learning environments induce impulses for students' comprehensive learning processes. By referring to the educational philosophy of Dewey (2008), Wittmann points out that the logically 
ordered mathematical content is the basis used to describe the earlier and later stages of a single developmental learning process. For teaching mathematics, this process has to be viewed from two directions as aptly outlined below:

From the side of the child, it is a question of seeing how his experience already contains within itself elements facts and truths of just the same sort as those entering into the formulated study; and, what is of more importance, of how it contains within itself the attitudes, the motives, and the interests which have operated in developing and organizing the subjectmatter to the plane which it now occupies. From the side of the studies, it is a question of interpreting them as outgrowths of forces operating in the child's life, and of discovering the steps that intervene between the child's present experience and their richer maturity. (Dewey 1966, p. 11)

With respect to mathematics, the following core characteristics of substantial learning environments reflect these thoughts:

- They represent fundamental objectives, contents, and principles of mathematical learning at a particular level.

- They are based on fundamental mathematical content, processes, and procedures beyond this level and contain a wealth of mathematical problems ('exercises').

- They can be flexibly tailored to the specific conditions of a particular class.

- They integrate mathematical, psychological, and educational aspects of mathematics teaching and learning and therefore provide a rich field for empirical research

- (Wittmann 2001a, p. 2).

In order to design substantial learning environments, Wittmann (1995) considers the mathematical substance of the exercise, or in other words the 'epistemological structure of the topic', to be of particular importance. The latter provides the basis of composing mathematical activities for children at very different ages and levels. However, the mathematical substance does not appear as the systematic deductive structure of already 'finished' mathematics. Rather, it recalls Freudenthal's ideas and helps with the understanding of mathematics from a learner's perspective on the subject.

Classical substantial learning environments are, for example, arithmogons or number walls (Fig. 3.1).

The rules for calculating within the number wall or the arithmogon are very simple: Add the numbers of two adjacent fields and write the sum in the field above (number wall) respectively outside of the corresponding side (arithmogon). Based on

Fig. 3.1 An arithmogon (Wittmann 2001b, p. 193) and a number wall
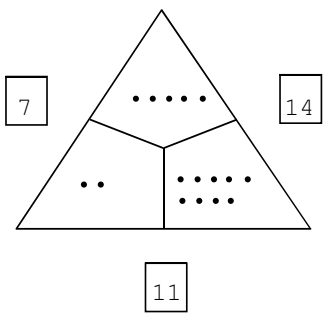

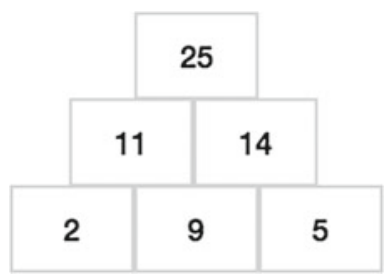


the mathematical substance of these two exercises, substantial learning environments that vary in their focus of initiating deep learning of mathematics can be developed (see Fig. 3.2).

For example, one can find different problems for adding and subtracting numbers within the triangle by offering different numbers inside and/or on the outside of the triangle. The operational structure of the arithmogons can be examined by changing the entries in the fields systematically (see Fig. 3.3). In this sense, the sequence of tasks and problems can arise naturally from the mathematical substance of the context.

While the epistemological structure of the subject offers an essential orientation for evaluating learning environments, the creative act of designing new learning environments ultimately is not explicitly comprehensible and explainable. This depends mainly on the 'constructive imagination' of the designer (Wittmann 1995). Nonetheless, according to Wittmann (2015), the following characteristics provide orientation for developing substantial learning environments: mathematical substance and richness of activities at different levels, assessment of cognitive demands, curricular fit (in terms of content and general learning objectives), curricular coherence and consistency, curricular coverage, exercise potential, and the estimation of the time required. Ultimately, mathematics education considered as a DESIGN SCIENCE is a creative science, based on the solid knowledge of fundamental mathematical structures and processes combined with the profound knowledge of children's learning, professional learning requirements, and objectives of mathematics teaching, also with a reference to curricular frameworks.

For Wittmann (2001b), substantial learning environments are conducted as teaching experiments, which do not encompass complete and detailed lesson units. Instead, to learners substantial learning environments are revealed as a space for error and discovery as well as a path of their own learning.

Fig. 3.2 The algebraic structure of an arithmogon and a number wall
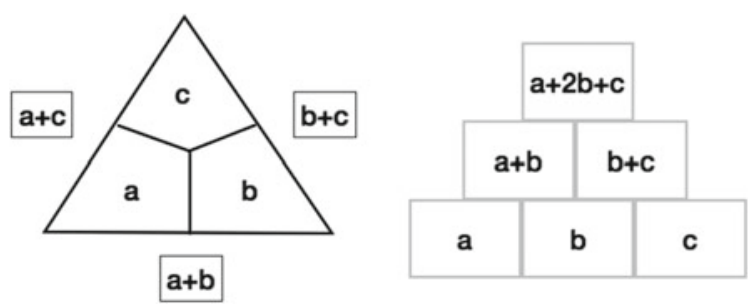

Finde passende Zahlen. Wie viele Möglichkeiten?

(a)

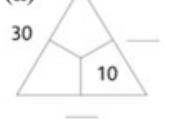

(b)

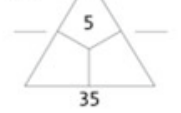

(c)

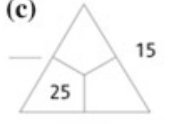

Wie ändern sich die Außenzahlen? Finde die Innenzahlen.

(a)
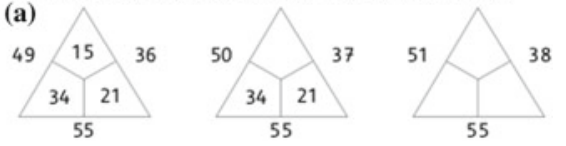

Fig. 3.3 Variations of problems: 'Find the suitable numbers. How many possibilities?' and 'The outside numbers are changing. Find the inside numbers' (Nührenbörger and Schwarzkopf 2017) 


\title{
3.2.3 Conducting Teaching Experiments for Improving the Design
}

The quality of the learning environments developed by Wittmann has been continuously reviewed in collaboration with teachers, and so the processing of learning environments has undergone cyclical revisions. Echoing Piaget's clinical interviews, Wittmann (1995) proposed 'clinical teaching experiments' as a suitable empirical method:

\begin{abstract}
As a result we arrive at 'clinical teaching experiments' in which teaching units can be used not only as research tools, but also as objects of study. The data collected in these experiments have multiple uses: They tell us something about the teaching/learning processes, individual and social outcomes of learning, children's productive thinking, and children's difficulties. They also help us to evaluate the unit and to revise it in order to make teaching and learning more efficient. [...] Clinical teaching experiments can be repeated and thereby varied. By comparing the data we can identify basic patterns of teaching and learning and derive wellfounded specific knowledge on teaching certain units. (Wittmann 1995, p. 367f.)
\end{abstract}

Following the idea of 'lesson studies' (Fernandes and Yoshida 2004), a group of teachers (and researchers) work together by planning, teaching and discussing a concrete teaching unit. In order to finally revise the teaching unit, the teachers not only discuss the documents of the lesson but their impressions and observations as well, with reflection on the initiated processes. Learning environments in particular serve as a basis to closer investigate the teaching experiments with the mathematics teaching and learning processes, especially the mathematical thinking of students.

For example, within the project PEnDEL (practice-oriented development projects in discussion with educators and teachers; Schwarzkopf et al. 2018), different teaching experiments are designed to provide a rich frame for comparing tasks with a view on the mathematical structures. The teaching experiments are based on the assumption that individual learning processes always depend on an active discussion of mathematical issues and, at the same time, are also linked to social interactions where such discussions are realized. Therefore the didactical principles (e.g. operative principle, natural differentiation, spiral principle, genetic principle) for designing the teaching experiment are enriched by 'productive irritations' for fostering mathematical argumentation processes (Nührenbörger and Schwarzkopf 2016). To this end, the pupils should challenge routinely generated expectations in the processing of assignments or in a mathematical observation. Such a productive irritation should create an opportunity for the children to recognise a subject-specific conflict, while on the other hand trying to resolve it argumentatively. In this sense, a productive irritation needs to be ultimately understood as a deviation from received expectations that require resolution.

Next, we provide an example of a short teaching experiment, fostering the mathematical argumentation processes of children in a primary class (4th class) (Nührenbörger and Schwarzkopf 2016). First, the children calculate a sequence of number walls; increasing the number in the bottom box on the right and decreasing the number in the bottom left box by the same amount leaves the number at the top of the wall constant (keeping the same number in the middle of the bottom row) (see Fig. 3.4). 
The children calculate the number at the top and try to find arguments to explain the constancy of the number at the top of the wall. However, having calculated some of these tasks, the students just focus on the changing bottom numbers without reflecting on the structure of the number wall (see Fig. 3.5). For example, the written document refers to the relation of the corner numbers $(+10$ and -10$)$ as argument for explaining the equality of the results.

For rich argumentation, it is important that the children reason not only on a number level, but take into account the terms for calculation. In a complement task, the children are confronted with another number wall that does not exactly fit the previously discovered pattern (see Fig. 3.6). So, the question for the children was: Will the number at the top of the wall change or not? This is considered a productive irritation, helping the children to become aware of the special function of the number in the bottom middle box.

The example shows how substantial learning environments pursue not only the goal to provide mathematical learning opportunities for students, but to enrich teachers' understanding of their learning processes. In view of reaching the ultimate goal of fostering children's argumentation, the first approach of designing the learning environment is only partly successful. Based on the initiated reasoning, the teaching experiment has been modified so that conducting cyclical teaching experiments is an essential methodological prerequisite within the DESIGN SCIENCE approach.
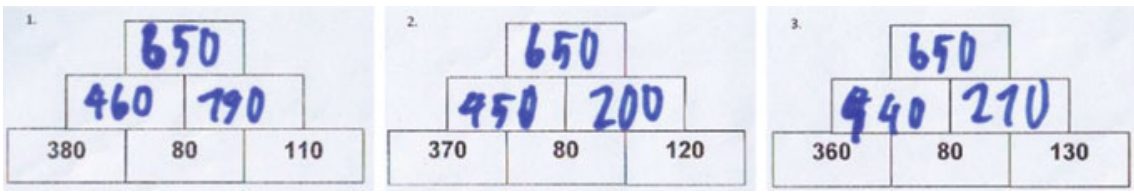

Fig. 3.4 An operative series of number walls with constant number at the top of the wall

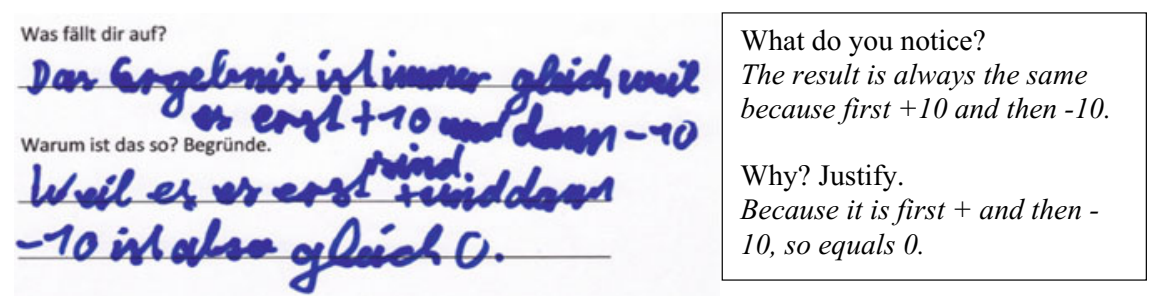

Fig. 3.5 A child's explanation of the constant number at the top of the number walls (see Fig. 3.4)

Fig. 3.6 A new series of number walls with a constant number at the top of the wall
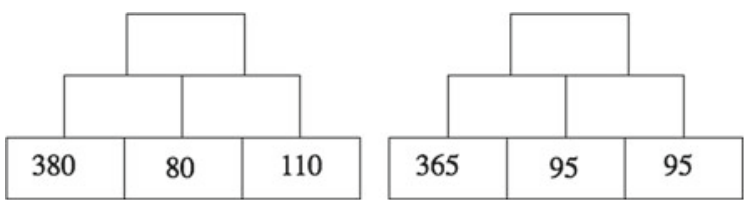
Designing and researching substantial learning environments has substantially permeated research in mathematics education. Chapter 2 and this chapter provide some current examples that centre research on such learning environments, but pursue different emphasis as well. Thus, the concept of DESIGN SCIENCE has undergone some change, both in terminology as well as methodology.

\subsection{Identifiying and Following Key Ideas as a Design Principle}

Research in mathematics education as a DESIGN SCIENCE in line with Wittmann (1995) puts emphasis on a constructive element, i.e. designing substantial learning environments. As outlined in Sect. 3.2, these are based on fundamental mathematical content and represent fundamental objectives (Wittmann 2001a). One pending issue still to be resolved is identifying content, which is fundamental in this sense. This is where key ideas of mathematics come into play.

In this chapter the different meanings of these key ideas are specified. Afterwards, some brief insights into two examples of using key ideas in research projects are given. Furthermore, in the projects' descriptions the interweaving relation between key ideas as normative settings and empirical research is addressed.

\subsubsection{Theoretical Reflections on Key Ideas of Mathematics}

In the early 1970s - around the same time as the founding of the German Society of Didactics of Mathematics (GDM) — different studies on fundamental ideas of mathematics and mathematics education started to appear in Germany. The papers at that time try to assure and reassure the newly established community of its purpose and aims. Some of the studies focus on mathematical behaviour and mathematics as an activity. Others address mathematics education as a recently encountered independent research field. And last not least, studies put an emphasis on the scope of mathematics contents and topics.

The concept of structuring the 'body of knowledge' by fundamental ideas dates back to Bruner (1966a, p. 41). In Bruner's work various terms, such as 'basic idea', 'general idea', or 'fundamental idea', can be already identified (Bruner 1966b). In subsequent studies and literature the various terms are taken up by others or even the scope is broadened by big ideas, core ideas, etc.

The understanding of key ideas in the current studies seems to depend on miscellaneous underlying meanings. It is indeed futile to attempt to nail down each term in its specific meaning, although the respective focus on (key) ideas can be identified. Bruner (1966b) has already used such ideas with the aim of at least two objectives: He merges thoughts on basic subjects and the grasping of general principles or atti- 
tudes of mathematical thinking by the learner whilst working on these basic contents. In a nutshell, the aim of using key ideas is twofold: a focus on specific mathematical thinking processes on the one hand, and a focus on fundamental mathematical content on the other.

\subsubsection{Focus on Key Ideas of Mathematical Thinking}

In different papers, mathematical thinking is attributed to special objectives and behaviour (for more detailed information, see Vohns 2016). For instance, Bender and Schreiber (1985) record inter alia ideation and exhaustion to be fundamental for geometrical thinking. Vollrath (1978) characterizes no specific mathematical thinking types but defines ideas to be fundamental indirectly by the impact of such ideas within an individual thinking process:

\footnotetext{
When I speak of ideas in the following, I mean the crucial thought of a theme, the substantial core of a consideration, a fruitful inspiration while solving a problem, the leading question of a theory, the central statement of a proposition, the underlying relations of an algorithm, and the images linked to conceptualization. (Vollrath 1978, p. 29, translation by the author of this paper)
}

Other studies outline the understanding of mathematical ideas in the context of learning and mathematics education, e.g. Winter (1975) identifies general ideas of learning mathematics in using heuristic strategies, proving, mathematising, formalizing, and using mathematical skills. The attempt to describe certain cognitive activities to be typical of mathematical thinking is still ongoing. Current studies mostly reflect on the register that the Organisation for Economic Co-operation and Development (OECD 2013) identifies as so-called mathematical literacy and the therein described mathematical processes "formulating situations mathematically; employing mathematical concepts, facts, procedures, and reasoning; and interpreting, applying and evaluating mathematical outcomes" (p. 9) and fundamental mathematical capabilities. Moreover, in this view it is common to differentiate mathematical thinking gradually in competence levels which are denominated to be reproductive, connective, or reflective.

In summary, this perspective tries to outline the specific components of thinking which define thinking processes and attitude to be mathematical. This meaning of fundamental or key ideas is taken up in current standards and curricula as so-called process goals or principles. Hence, they define fruitful teaching and learning interactions, attitudes, and beliefs towards favourable terms of learning mathematics.

\subsubsection{Focus on Key Ideas of Mathematical Content Cores}

In a different perspective, it is not the thinking and interaction processes that are focused upon but the core content areas. The approach used here follows a constructive orientation in order to provide practical and concrete designs (Wittmann 1974). 
Learning mathematics is not an event but a lifelong process. Mathematical key ideas are one possible answer to identify strands-aligned to age and level of development-but also to keep in mind the big picture and connectivity. Bruner recommends to present knowledge as a connected set of facts in a sufficient structure to be re-examined throughout both primary and secondary school (Bruner 1966b).

The scope of mathematical contents, which is considered to be crucial and substantial, constitutes key ideas. Of course it is necessary to condense mathematical contents in such ideas which are continuative and expandable. This concentration in key ideas allows one possible orientation for researchers and teachers.

In order to provide teachers with an orientation beyond substantial learning environments, it is useful to summarize basic knowledge about mathematics, learning, and teaching mathematics in didactical principles. One principle, for example, is "orientation on fundamental mathematical ideas". (Wittmann 2016, p. 26)

In accordance with Whitehead's (1929) view on mathematical education, Wittmann follows the idea to restrict the teaching contents (Table 3.1) and not to choose any subject but the mathematical important ones in line with Freudenthal (1983). Ideally, key ideas are never out of fashion because mathematics and its structural important subjects do not change.

Key ideas make it possible to get an overview of important topics from kindergarten up to grade 12. They allow for the understanding of content areas at a glance. This possibility should not be underestimated especially by both teachers and researchers. Focusing on the relations and connections of topics in mathematics education stops the whole picture from being put on the line and from creating isolated or disconnected (Whitehead 1929) teaching-learning-environments, which would be useless for mathematical literacy or the development of fundamental mathematical thinking. At best, key ideas, metaphorically spoken, function as the backbone of the living body of the lifelong mathematical education process.

For research, key ideas function as a framework for designing substantial learning environments. Lifelong learning in terms of a spiral curriculum allows individuals

Table 3.1 Key ideas (Wittmann and Müller 2012, pp. 160-161)

\begin{tabular}{l|l|l}
\hline Ideas of arithmetics & Ideas of geometry & Ideas of stochastics \\
\hline Number line & $\begin{array}{l}\text { Shapes and their } \\
\text { constructions }\end{array}$ & $\begin{array}{l}\text { Quantitative description of } \\
\text { random events }\end{array}$ \\
\hline $\begin{array}{l}\text { Calculating, properties, } \\
\text { calculating strategies }\end{array}$ & Operating with shapes & Probability \\
\hline Number system & Co-ordinates & Random experiments \\
\hline Algorithms & Measurements and formulas & Formulas \\
\hline $\begin{array}{l}\text { Arithmetical patterns and } \\
\text { structures }\end{array}$ & $\begin{array}{l}\text { Geometrical patterns and } \\
\text { structures }\end{array}$ & $\begin{array}{l}\text { Stochastic patterns and } \\
\text { structures }\end{array}$ \\
\hline Numbers in daily life & Shapes in daily life & Random events in daily life \\
\hline \multicolumn{2}{l}{ Translation in number- and shape-language } & Stochastic modelling \\
\hline
\end{tabular}


to deepen their understanding while working on these designed tasks in continuous strands of key ideas.

\subsubsection{Two Examples of Using Key Ideas}

Key ideas can be seen as normative settings determined by mathematics itself, even though empirical research is consistent with these ideas. On the one hand, mathematics education as a DESIGN SCIENCE (Wittmann 1995) needs researchers and expert practitioners to translate the ideas into suitable learning environments and tasks. In doing so, the design naturally takes into account empirical findings according to learning conditions which are psychologically and educational sound. On the other hand, mathematics education research is requested to evaluate the effects and impacts of the implementation of the environments on students' abilities and mathematical development.

The key ideas serve as designing principles for substantial learning environments. The research responsibility is to identify crucial key ideas and learning trajectories and to implement these ideas into tasks and SLEs. Consequently, these activities provide access to the key ideas and allow sensibility for the main subjects:

The language in which substantial learning environments are communicated is understandable to teachers, so reflective practitioners have good starting points to transform what is offered to them into their context and to adapt, extend, cut, and improve it accordingly. (Wittmann 2016, p. 25)

The projects briefly presented in this chapter are assigned to the essential phases of transition concerning primary school, i.e. the transition from kindergarten to school and the transition from primary to secondary school. Both approaches aim to support the smooth transition phases by pinpointing mathematical key ideas.

\subsubsection{Mathematical Key Ideas in Kindergarten}

Early mathematics in kindergarten is commonly regarded as being an important lifelong learning process. Nevertheless, the scope of core areas has not yet been entirely agreed upon. The role of key ideas here is to suggest one possible approach of an overview of important subjects.

In our design and research project MAIKE (Mathematics in Kindergarten), we take into account the wide range of competencies which are considered to promote a successful school beginning, different content areas such as number and operations, geometry and spatial sense, measurement, pattern, etc. as described in the learning paths or the big ideas (e.g. NAEYC \& NCTM 2010; Wittmann 2009).

In this project, the design of a little application for tablet use is the specific vehicle for allowing children, parents, and kindergarten educators to gain access to the normative set of important key ideas. The design idea is to provide awareness 
of the wide range of suitable mathematical contents (for both children and adults). The purpose of the digital feature is to tempt children and adults to explore real life mathematical objects and analogous situations.

Of course the design of tasks and learning situations has to be accompanied by empirical research on the use, accessibility, and impact of the substantial learning environments: "The big ideas or vital understandings in early childhood mathematics are those that are mathematically central, accessible to children at their present level of understanding, and generative of future learning" (NAEYC \& NCTM 2010, p. 6). For instance, first case studies indicate substantial differences between the abilities and competencies shown in an interview versus the digital play environment (Birklein and Steinweg 2018).

Key ideas in this research end up in designing digital learning environments. They thereby offer adults the chance to become aware of the mathematical contents and activities suitable for kindergarten children, and are helpful to overcome the widespread uncertainty of kindergarten educators, which subjects should be provided in early maths education. Furthermore, they may hopefully serve as an implicit inservice education to kindergarten teachers (and parents).

\subsubsection{Key Ideas of Algebraic Thinking}

In the field of algebraic thinking, the particular situation in Germany asks for key ideas for some other reason. Algebraic thinking is not mentioned in primary curricula and therefore the fundamental rule in the interplay of contents and topics is neglected (Steinweg et al. 2018). Hence, key ideas in this branch of mathematics pave the way to become aware of algebraic ideas as a possible subject in primary mathematics education.

International research indicates major ideas and core areas of algebraic thinking (e.g. Kaput 2008), even though these registers are not suitable for German teachers and thus have no influence on teaching-learning-situations in schools. Key ideas have to be made accessible in the specific cultural context. Furthermore, they have to take into account the existing ideas of mathematics and work out the interplay between the common and the supposedly new ideas. Only the connectivity of key ideas ensures dissemination and implementation in classrooms. Moreover, the sensible emphasis on the interweaving of contents protects classroom interaction against disconnected and isolated teaching.

The major branch of patterns and structures, which is given in the national standards (KMK 2004), is taken up as a possible link to algebraic thinking. This content area is controversially discussed and difficult to grasp for teachers. The offer of algebraic key ideas thereby gives one possible answer to the open question of which topics might be condensed in this twosome concept. Consequently, the key ideas of algebraic thinking are formulated in the spirit and wording of patterns and structures: patterns (and structures), property structures, equivalence structures, and functional structures (Steinweg 2017). 
Exemplarily, one SLE in the idea of property structures is sketched here. Numbers have certain properties, which can be discovered and described. For instance, the divisibility relation between natural numbers is essential in mathematics. The abstract relation can be made accessible if the product is regarded as a rectangle area with a given length and width, k and a (see Fig. 3.7).

The rectangle has the area $b$ which is - for given a and $k$ - equal to the number of squares in the field on a piece of grid paper. Many mathematically sound activities arise from this idea of rectangles as a representation of factors as edge length. Special numbers that only have two dividers can be identified as numbers with only one possible representation (prime numbers). Numbers that can be divided by $3,4,5$, etc. can be found and compared.

If the divisibility by two is investigated, odd and even numbers can be displayed. Moreover, not only the properties of numbers but the properties of additive operations on these numbers can be investigated by children. The introduced representation of rectangle areas allows the discovery of the remarkable behaviour of the sums of odd addends to be even (see Fig. 3.8).

This example illustrates the impact of key ideas put into concrete terms of learning environments and tasks. Key ideas allow teachers to become aware of main topics and fruitful tasks in order to initiate and enhance the chances of children's learning processes.

$$
\begin{gathered}
\forall a, b \in \mathbb{N}: a \mid b \\
: \Leftrightarrow \exists k \in \mathbb{N}, \\
\text { such that } b=k \cdot a
\end{gathered}
$$

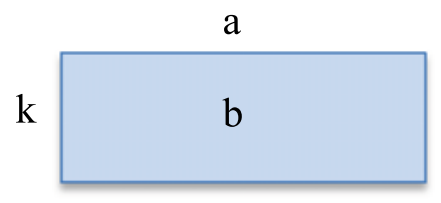

Fig. 3.7 The definition of the divisibility relation represented as a rectangle

Fig. 3.8 Properties of sums of odd and even numbers

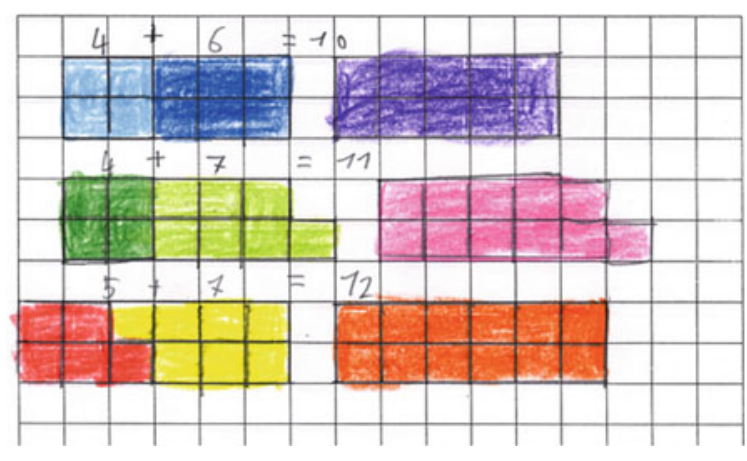




\subsubsection{Closing Remarks}

The two illustrations given above indicate the possibilities of key ideas. First of all they serve as the designing principles for researchers in a constructive understanding of mathematics education. They function as a framework for designing substantial learning environments and adequate material. In addition to the area of research therein (identifying key ideas and design), research thereafter is essential. This research evaluates and eventually adjusts the designed environments on the one hand, and monitors and supports children's learning processes and developments on the other.

For teachers, key ideas serve as guiding principles for classroom interaction. They allow for the awareness of core contents and to differentiate between important tasks and questions and less fruitful ones.

Teachers need to work with learners on the fundamental ideas behind topics. The Chinese teachers seem to me to be paying explicit attention and taking time over what I would call core awareness, or threshold concepts. Everybody can work at those, everybody can take that in, anybody who can get to school can comprehend them. (Mason 2016, p. 45)

Key ideas enhance the chances of children's learning processes. At the same time they put emphasis on the core objectives of children's developments. The important steps and milestones can be seen as being structured along the key ideas for both teachers and children.

\subsection{Describing Number Patterns. an Example for Designing a Learning Environment}

Within his concept of mathematics education as a DESIGN SCIENCE, Wittmann points out different options to combine design with empirical research (Wittmann 1995). One is the ongoing design, evaluation and revision of learning environments in cyclic teaching experiments. This iterative approach is a common characteristic of comparable accounts to intertwine design and research known as design research or design-based research. Combining design and empirical research is a suitable methodological account when an educational problem is recognised and there are not yet sufficient solutions available to 'solve' this problem in educational practice (Plomp 2013; Kelly 2013; Gravemeijer 1994). Sketching the problem should form the starting point of every design research project, and therefore, I will briefly outline the background and the problem of the project presented here: Why is it necessary to design learning activities on describing number patterns?

Communication competences, which are specific for the discipline, are part of revised mathematical curricula and standard listings all over the world. Following the NCTM standards in the US, for example, students should learn to "organize and consolidate their mathematical thinking through communication", to "communicate their mathematical thinking coherently and clearly to peers, teachers and others", 
and to "use the language of mathematics to express mathematical ideas precisely" (NCTM 2000). These competences do not only contribute to the communication between individuals, but through communicating about mathematics, students should deepen their individual understandings of mathematical concepts and procedures. Writing about mathematics in particular has this effect because, in contrast to oral communication, a much more precise language and complete explanation and thus a deeper analysis is required (Morgan 2001; Elliott 1996). Morgan (1998, p. 25) speaks in this context of 'writing-to-learn' mathematics. But she also points out that these writing competences of students do not evolve naturally and spontaneously; teachers should plan focused opportunities for students to practice 'learning-to-write' mathematics.

A simple and not too complex example for 'writing-to learn' and 'learning-towrite' mathematics in the first years of primary school are the so-called Entdeckerpäckchen (Discovering Pacs) (see Fig. 3.9). These are series of calculations that emerge through operative variations of the given numbers. Besides practising computational competences, students can also discover a pattern and continue it (What comes next?), they can investigate the connections between the variations of the given numbers and the results (What happens with the result?), and they can describe the discovered patterns (What do you notice?).

The patterns in Discovering Pacs are based on general operation-specific properties (e.g. the sum remains constant if the summands are varied in the opposite direction by the same amount, or the difference remains constant if minuend and subtrahend are varied in the same direction by the same amount). By recognising the patterns and connections and particularly by formulating precisely and writing down their discoveries, students can extend their understanding of the arithmetic operations by exploring these properties (in the sense of Morgan: 'writing-to-learn' mathematics). By focusing on general properties of operations and by stimulating typical mathematical processes like generalization and abstraction, describing patterns in Discovering Pacs can be seen as a valuable pre-algebraic activity (Steinweg 2013). But in order to fully initiate these learning processes, it is not sufficient just to ask students to write down what they notice; students' first attempts to describe number patterns show often potential to improvement (Frobisher and Threlfall 1999; Steinweg 2004). These first attempts can be used as a starting point for further discussions, reflections and revision for formulating descriptions of number patterns in the classroom, so that the students have the opportunity to 'learning-to-write'

Fig. 3.9 Examples for discovering pacs

$$
\begin{array}{ll}
65+11= & 65-11= \\
55+21= & 75-21= \\
45+31= & 85-31= \\
35+41= & 95-41=
\end{array}
$$


mathematics. It was the aim of the project presented here to design such learning opportunities.

\subsubsection{Stages of the Design Research Project}

Characteristic for a design research project, a cyclic approach of designing, testing in teaching experiments, and revising and redesign was employed (van den Akker et al. 2006), similar to the concept of lesson studies (Lewis et al. 2006). With the project progressing, the teaching experiments took place under increasingly realistic conditions in classroom situations.

\subsubsection{Stage 1: Clarifying the Starting Points}

In an initial stage of the project, data was collected on how students in grade 3 describe number patterns in Discovering Pacs, if they were not accustomed to them through previous teaching. The aim of this stage was to document the instructional starting points on which the following learning activities could be built upon (Cobb and Gravemeijer 2008).

The analysis resulted in criteria to evaluate students' descriptions and provided examples that could be used as materials in classroom activities initiating discussions with students about the quality and quality criteria of number pattern descriptions. Besides the criteria- such as the extent of the description and accuracy and precision-it was interesting that some students described both variations and the positions on which these variations took place and others did not (see examples in Fig. 3.10).

\subsubsection{Stage 2: Interviews with Students}

After the initial stage, a first draft of learning activities was designed. Two of them, Beschreibungen vergleichen (Comparing Descriptions) and Beschreibungen verbessern (Improving Descriptions), required students to evaluate one or several given descriptions to a Discovering Pac, to think about what the author could have meant by writing this, and to suggest how the descriptions could be improved. The aim of these activities was to stimulate discussions and reflections with students upon the quality criteria of number pattern descriptions and applying them in order to find a better description. These two activities were tried out in teaching experiments (Wittmann 1995), in interviews with students from grade 3.

All participating students were able to criticize the given descriptions by implicitly referring to the quality criteria of number pattern descriptions. For example, as a reaction to the Discovering Pac at the left in Fig. 3.11, one student argues why he 


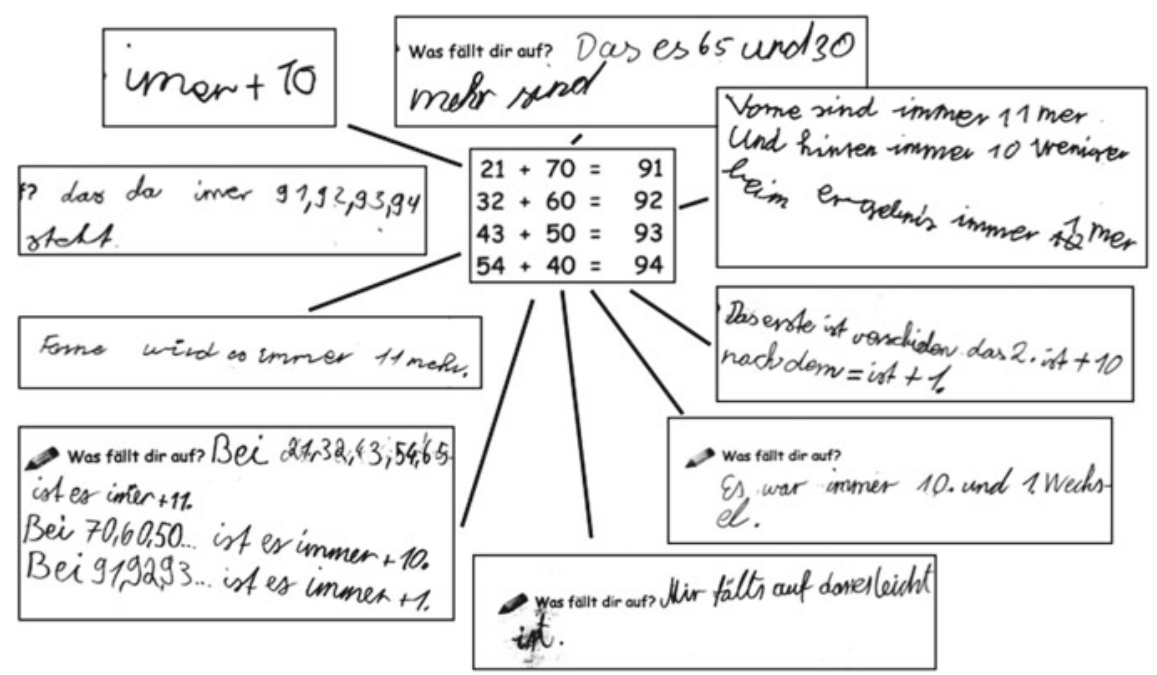

Fig. 3.10 Examples for descriptions (Translations, starting with the description at the top: "It's 65 and 30 more"; "In front, there are always 11 more, behind, there are always 10 less, the result is always 1 more"; "The first is different, the second is +10 , after the $=$ it is +1 "; "There are always 10 and 1 Changes"; "I notice that it is easy"; "At 21, 32, 43, 54, 65 it is always +11 . At 70, 60, 50... it is always +10 . At $91,92,93, \ldots$ it is always +1 "; "In front, there are always 11 more."; "There is always 91, 92, 93, 94."; "Always +10")

$$
\begin{aligned}
& 35+5=40 \\
& 36+4=40 \\
& 37+3=40 \\
& 38+2=40
\end{aligned}
$$

Leon writes:

The numbers at the front are different.

$$
\begin{aligned}
& 15+10=25 \\
& 15+20=35 \\
& 15+30=45 \\
& 15+40=55
\end{aligned}
$$

Mary writes:

It's always one more.

Fig. 3.11 Two examples for the learning activity Improving Descriptions that were used in interviews (translated by the author of this paper, see Link (2012) for the originals)

doesn't like the description: "Because it depends not only on the numbers here at the front. You have to look also at the numbers behind (points to the column with the second summands) and here at the back (points to the column with the sums)." (Translated by the author.) In reaction to the Discovering Pac and the description to the right, another student says: "Because what is always one more, the tens or the ones [...] It could also be that he means the ones, but this isn't correct." (Translated by the author.) While the first student criticizes the extent of the given description, the second refers to the accuracy of the description as it is not clearly stated which object or position is varied 'always one more'. 


\subsubsection{Stage 3: Teaching Experiment in Two Classrooms}

The interviews have shown that it is possible to reflect with third graders on quality criteria of pattern descriptions. The two learning activities were then used with three additional activities in a teaching experiment in two classes consisting of seven lessons, including a test at the beginning and at the end of the experiment. Teaching materials were provided for all five learning activities (work sheets for students, posters, teacher instructions at the beginning and the end of the lessons) and discussed with the math teachers of both classes. The math teachers conducted the teaching experiment in their own classes, the researcher was present during the lessons as co-teacher.

One of these five learning activities had the name Markieren und Schreiben (Colouring/Highlighting and Writing). In this learning activity, the students are asked to use colour to highlight all the places in the Discovering Pacs where they noticed a pattern or something else that they found noteworthy. In a second step, they should write a sentence for every colour used. The intention was for the students to first document their discoveries in a nonverbal way and then use the colours as a scaffolding to write down everything they discovered. The colours could also be used with finalising the writings as reference to the positions in the Discovering Pac (where something is remarkable), as a help if suitable words or expressions to verbalize this aspect of the pattern are missing. The students used this help in very different and creative ways. Some used coloured dots to express what position their sentence is referring to (see Fig. 3.12, on the left), others used the colours in a verbalized way: "At green ..." or "The blue numbers..." (see Fig. 3.12, on the right).

The expression of positions by colours can work as a 'bridge' between informal, everyday language and mathematical language, particularly as the students will then proceed to find and collect words and expressions to verbalize the positions in the Discovering Pacs without the use of colours. This way, technical terms like 'summand' or 'sum' can be introduced by the teacher, too.

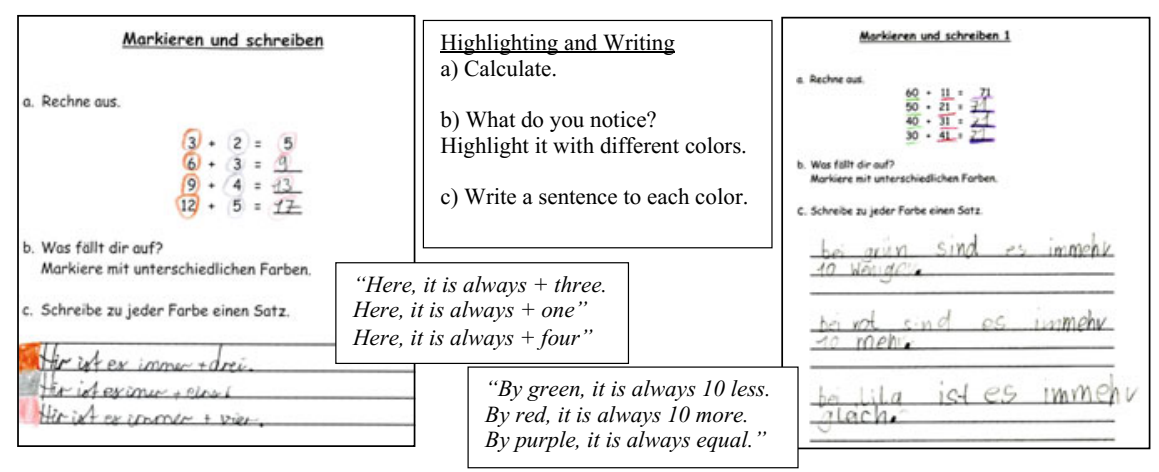

Fig. 3.12 Student documents from the learning activity Colouring/Highlighting and Writing 
In contrast to the test at the beginning of the teaching experiment, the extent of the number pattern descriptions increased noticeably among most of the students who had participated in this learning activity. Almost all students were able to verbalize the positions in the Discovering Pacs or make a reference to the coloured markings they applied themselves.

\subsubsection{Stage 4: Evaluation of the Materials in Seven Classrooms}

Based on the results of the teaching experiments in stages three and four, all materials were revised and modified. In a final stage of the project, these materials were used in seven classrooms. This time, the teachers received a short introduction, but they worked alone and independently with the materials in their classrooms. At the end, feedback from the participating teachers was collected, and all documents of students' work, including tests at the beginning and at the end of the teaching unit, were provided for further analysis. Evaluations of the tests show that the students' descriptions of number patterns after the unit became more extensive and more accurate, and the students verbalized positions in the Discovering Pacs much more frequently than before (Link 2012).

\subsection{From Design Science to Design Research: Trends and Developments in Germany}

Throughout the last two decade(s), the strong German tradition on DESIGN SCIENCE, a heritage of Erich Wittmann and others, has evolved into the research program of DESIGN RESEARCH in which Wittmann's focus on designing learning environments for developing mathematical structures is complemented by empirical studies, investigating the learning processes initiated by the design, and aiming at contributions to theory as well as to practical designs. This brief overview illustrates how the German tradition gives a slightly different emphasis to topic-specificity than in other well established approaches to DESIGN RESEARCH.

\subsubsection{From DESIGN SCIENCE to DESIGN RESEARCH-Lines of Development in Dortmund}

In Dortmund, the pathway from DESIGN SCIENCE to DESIGN RESEARCH started quite early, as already Wittmann emphasized. "In order to develop didactics as design science, it is important to find ways of connecting design and empirical 
research" (Wittmann 1995, p. 337). An important motor for this enhancement of DESIGN SCIENCE by empirical investigations was Heinz Steinbring, who joined the Dortmund group from 1995 to 2004 . He contributed substantially by empirical investigations of learning processes on the micro-level, as evidenced for example in his seminal book (Steinbring 2005) in which he explored the processes of knowledge construction by an epistemological perspective on the micro level, emphasizing the need to mentally construct structures and meanings.

Other substantial influences for this enhancement by empirical investigations were given by the tight connection to the Freudenthal Institute (Treffers, van den HeuvelPanhuizen, and others) and its program of developmental research (Gravemeijer 1998) which was later called DESIGN RESEARCH (especially Gravemeijer and Cobb 2006).

From 2004 to 2009, a new generation of professors started working in Dortmund. They jointly decided to continue the work of Wittmann and Müller by consequently intertwining both the strong mathematical focus in topic-specific research and development (following Wittmann 1995) and the deep empirical focus on processes of knowledge construction on the micro level (following Steinbring 2005; Gravemeijer and Cobb 2006).

\subsubsection{Topic-Specific Didactical DESIGN RESEARCH with a Focus on Learning Processes-A Model for DESIGN RESEARCH}

For elaborating the Dortmund research model of Topic-specific Didactical DESIGN RESEARCH with a focus on learning processes, four main working areas have been specified as printed in Fig. 3.13. Meanwhile, several Ph.D. projects and other projects have been conducted in this model.

Developing designs, conducting and analysing design experiments and developing local theories on teaching and learning processes are typical working areas appearing in many models of DESIGN RESEARCH (e.g. Plomp and Nieveen 2013). The specific strong emphasis on processes on the micro level have been justified and theoretically embedded by other researchers (e.g. Gravemeijer and Cobb 2006). The strong topic-specific content focus, in contrast, appears less often in DESIGN RESEARCH projects internationally, but reflects the German tradition of Stoffdidaktik (Hußmann et al. 2016). In the Dortmund model, the strong content focus is realized by establishing a separate working area "specifying and Structuring learning contents" for which typical leading questions, methods and connections to the empirical work have been made explicit by Hußmann and Prediger (2016), see Table 3.2. 
Table 3.2 Typical questions on four levels for specifying and structuring the content (Hußmann and Prediger 2016, p. 36)

\begin{tabular}{|c|c|c|}
\hline & $\begin{array}{l}\text { Specifying the content (selecting } \\
\text { aspects and their backgrounds) }\end{array}$ & $\begin{array}{l}\text { Structuring the content (relating and } \\
\text { sequencing aspects, including } \\
\text { connecting points for long-term } \\
\text { processes) }\end{array}$ \\
\hline $\begin{array}{l}\text { Formal } \\
\text { level }\end{array}$ & $\begin{array}{l}\text { Which concepts and theorems have to } \\
\text { be acquired? } \\
\text { Which procedures have to be acquired, } \\
\text { and how are they justified formally? }\end{array}$ & $\begin{array}{l}\text { How can the concepts, theorems, } \\
\text { justifications and procedures be } \\
\text { structured in logical trajectories? } \\
\text { Which connections are crucial, which } \\
\text { are contingent? } \\
\text { How can the network between } \\
\text { concepts, theorems, justifications and } \\
\text { procedures be elaborated? }\end{array}$ \\
\hline $\begin{array}{l}\text { Semantic } \\
\text { level }\end{array}$ & $\begin{array}{l}\text { What are the underlying big ideas } \\
\text { behind the concepts, theorems and } \\
\text { procedures? } \\
\text { Which basic mental models and } \\
\text { (graphical, verbal, numerical and } \\
\text { algebraic) representations are crucial } \\
\text { for constructing meaning? }\end{array}$ & $\begin{array}{l}\text { How do the underlying ideas and } \\
\text { meanings relate to each other and to } \\
\text { earlier and later learning contents? } \\
\text { How can the meanings be successively } \\
\text { constructed by horizontal } \\
\text { mathematization in the intended } \\
\text { learning trajectories? } \\
\text { Which trajectories of vertical } \\
\text { mathematization have to be elicited in } \\
\text { order to initiate the } \\
\text { invention/discovery of core ideas, } \\
\text { concepts, theorems and procedures? } \\
\text { How can the intended learning } \\
\text { trajectories be sequenced with respect } \\
\text { to the logical structure? }\end{array}$ \\
\hline $\begin{array}{l}\text { Concrete } \\
\text { level }\end{array}$ & $\begin{array}{l}\text { Which core questions and core ideas } \\
\text { can guide the development of the } \\
\text { concepts, theorems, and procedures? } \\
\text { In which context situations and by } \\
\text { which problems can the core questions } \\
\text { and ideas be treated exemplarily for } \\
\text { re-inventing the content? }\end{array}$ & $\begin{array}{l}\text { How can the meanings be successively } \\
\text { constructed in situations in the } \\
\text { intended learning trajectories? } \\
\text { How can the intended learning } \\
\text { trajectories be sequenced with respect } \\
\text { to the problem structure? } \\
\text { Which trajectories of horizontal } \\
\text { mathematization have to be elicited in } \\
\text { order to initiate the invention/ } \\
\text { discovery of core ideas, concepts, } \\
\text { theorems and procedures? }\end{array}$ \\
\hline $\begin{array}{l}\text { Empirical } \\
\text { level }\end{array}$ & $\begin{array}{l}\text { Which typical individual perspectives } \\
\text { of students (conceptions, ideas, } \\
\text { knowledge, ...) can be expected? } \\
\text { How do they relate to the intended } \\
\text { perspectives (resources vs. obstacles)? } \\
\text { What are origins of typical obstacles } \\
\text { or idiosyncratic conceptions? }\end{array}$ & $\begin{array}{l}\text { Which critical points in students' } \\
\text { learning path-ways are most crucial } \\
\text { (obstacles, turning points, ...)? } \\
\text { Which typical preconceptions or } \\
\text { previous knowledge can serve as } \\
\text { fruitful starting points? } \\
\text { How can the intended learning } \\
\text { trajectory be re- } \\
\text { sequenced with respect to students' } \\
\text { starting points and obstacles? }\end{array}$ \\
\hline
\end{tabular}




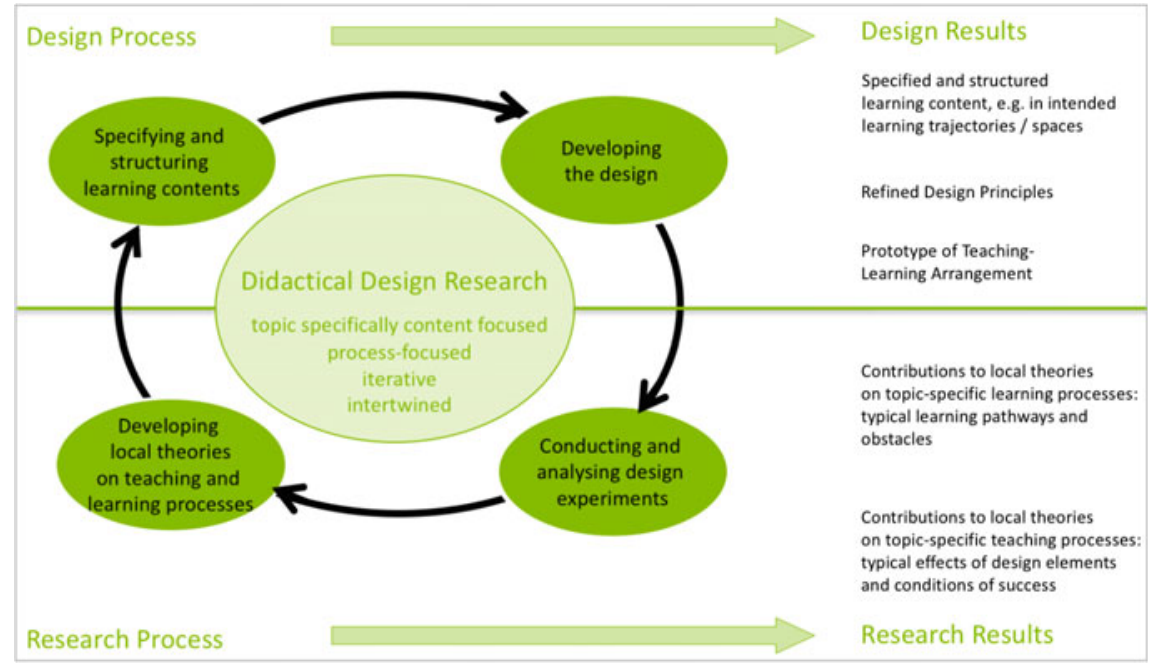

Fig. 3.13 Working areas in the model of Topic-specific DESIGN RESEARCH, applied across nine subject didactic disciplines (Hußmann et al. 2013; in English Prediger and Zwetzschler 2013)

\subsubsection{Illustration of Research Outcomes for a Typical Project: Exploring Individual Schematization Pathways}

One typical DESIGN RESEARCH project is described here in detail in order to illustrate typical outcomes. The exemplary project explores a well-known design principle: progressive schematization (Treffers 1987), according to which learning trajectories towards procedural rules can be organized as independent discoveries when the learning environment invites the students first to develop models for mathematical concepts and model-based informal strategies; then to explore the strategies and to discover pattern for progressively developing procedural rules.

The project (Glade and Prediger 2017) contributed to the theoretical and empirical foundation of the design principle of progressive schematization by empirically investigating students' individual schematization pathways on the micro-level for the specific case of part-of-part determination of fractions (see Fig. 3.14).

Structuring the learning content part-of-part in this case meant developing a schematization trajectory in several steps:

- starting with context problems

- establishing graphical models for the part-of-part

- developing informal strategies for determining part-of-part

- successively economizing the informal strategies in graphical procedures

- internalizing the informal strategies and underlying structures

- discovering formal procedure multiplication of fraction. 
In a series of laboratory set design experiments, nine pairs of sixth graders explored the part-of-part determination and progressively schematized their graphical strategies before discovering the procedural rule. A qualitative in-depth analysis of $760 \mathrm{~min}$ of video was conducted.

The analysis showed that progressive schematization is a multi-facetted process. The individual schematization pathways are much more diverse than the developed schematization trajectory, and cannot be described by internalization of graphical procedures alone. Instead, also finding inherent structures in the visualization and developing concepts is required before economizing is possible for students (Fig. 3.15).

A major contribution to the theory of schematization is that the schematization must be described by a dual progression in which the reduction of external actions are tightly intertwined with the compaction of concepts- and theorems-in-action. The project explores the students' pathways through successively compacting concepts on part-of-part, and hereby contributes to the topic-specific learning theory on fractions with typical pathways and obstacles. The reconstructed challenge to develop a justifiable procedural rule by connecting the informal and formal thinking also yields orientation for necessary design-elements, its effects and conditions of success. These empirical findings inform the theory as well as the redesign of the learning environment.

However, these kinds of Design Research studies have methodological limitations, so the results are restricted with respect to (1) the mathematical topic in view (only determining the part-of-part which is a simpler case than others, e.g., addition

Fig. 3.14 Part of part schematization: informal graphical solutions schematized into a rule
Fig. 3.15 Theoretical contribution: dual progression on external and internal side
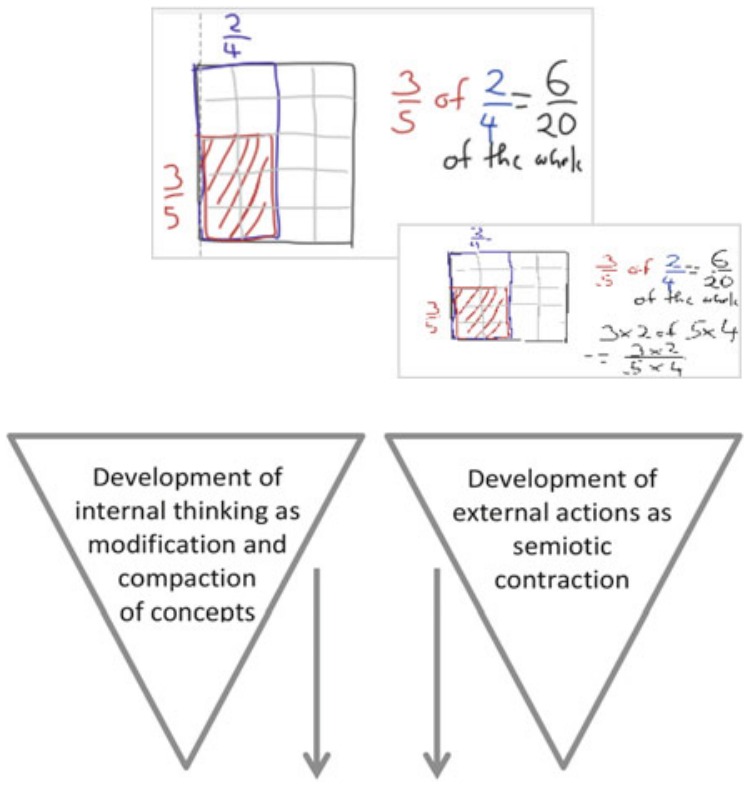
of fractions or long division), (2) the number of participants involved ( $\mathrm{n}=18)$, (3) the specific learning environments, and (4) the specific teacher in the design experiments. Hence the results are only local contributions to theory (Cobb et al. 2003), which are worth extending in future studies to a larger group of students and other learning environments and topics. By accumulating over several studies, a successive generalization to different topics and conditions will then be reached.

\subsubsection{Extensions of DESIGN RESEARCH to Other Subjects, Places, and to Teacher Education}

One milestone for the consolidation of DESIGN RESEARCH as a research program is its transfer from mathematics education to other disciplines. This was realized by the establishment of interdisciplinary graduate schools in Dortmund and other universities such as Bremen. In Dortmund, for example, the graduate school FUNKEN gathered nine subject matter education disciplines (including e.g. mathematics education, science education, language education and music) to collaborate within a joint research program (Hußmann et al. 2013). The establishment of interdisciplinary graduate schools reflects a growing interest not only in general education and mathematics education, but also to many other subject didactics.

Another extension concerns the shift from school classrooms to teacher education. For pre-service or in-service teacher education and professional development, DESIGN RESEARCH also proves to be a suitable research model to combine two aims, the development of suitable designs of learning environments for professional development and empirically investigating teachers' learning processes with typical pathways and obstacles for specific PD topics.

In the German Center for Mathematics Teacher Education (DZLM), especially, design experiments are put into a broader frame to substantiate professional development courses for teachers (Rösken-Winter and Sceszny 2016; Prediger et al. 2017). That is, research studies on the classroom level are needed to inform teachers' learning on the professional development level systematically. A deep understanding of students' learning of particular mathematics content and how this learning can be supported are both the basis for spreading professional development courses on a large scale. Within the scope of such courses additional teaching experiments, following the idea of DESIGN SCIENCE as outlined earlier in the chapter, complete the picture. However, the whole complexity of how teachers develop professionally demands a comprehensive DESIGN RESEARCH approach.

\section{References}

Akinwunmi, K., Lensing, F., Nührenbörger, M., Rösken-Winter, B., \& Schacht, F. (2016). Survey on the state of the art. In M. Nührenbörger, B. Rösken-Winter, Ch. Ip Fung, R. Schwarzkopf, \& 
E.Ch. Wittmann (Eds.), Design science and its importance in the german mathematics educational discussion (pp. 1-10). Rotterdam: Springer.

Bender, P., \& Schreiber, A. (1985). Operative Genese der Geometrie [Operative genesis of geometry]. Wien: Hölder-Pichler-Tempsky.

Birklein, L., \& Steinweg, A. S. (2018). Early maths via app use-Some insights in the EfEKt project. In Ch. Benz, H. Gasteiger, \& A. Steinweg et al. (Eds.), Mathematics education in the early years-Results from the POEM3 conference. Heidelberg: Springer.

Blum, W., \& Kirsch, A. (1991). Preformal proving: Examples and reflections. Educational Studies in Mathematics, 22(2), 183-203.

Bruner, J. (1966a). Towards a theory of instruction. Cambridge, MA: Harvard University Press.

Bruner, J. (1966b). The process of education. Cambridge, MA: Harvard University Press.

Cobb, P., \& Gravemeijer, K. (2008). Experimenting to support and understand learning processes. In A. Kelly, R. Lesh, \& J. Baek (Eds.), Handbook of design research methods in education (pp. 68-95). New York: Routledge.

Cobb, P., Confrey, J., diSessa, A., Lehrer, R. \& Schauble, L. (2003). Design Experiments in Educational Research. Educational Researcher, 32(1), 9-13.

Cohors-Fresenborg, E. (1993). Registermachine-As a mental model for understanding computer programming. In E. Lemut, D. Du Boulay, \& D. Dettori (Eds.), Cognitive models and intelligent environments for learning programming (pp. 235-248). Berlin: Springer.

Dewey, J. (1966). The child and the curriculum. Toronto, London: The University of Chicago Press (28th impression).

Dewey, J. (2008). Individuality and Experience. In J. A. Boydston (Ed.), The later works (1925-1927) (pp. 55-62). Carbondale: Southern Illinois University Press.

Elliott, W. (1996). Writing: a necessary tool for learning. The Mathematics Teacher, 89(2), 92-94.

Fernandez, C., \& Yoshida, M. (2004). Lesson study: A Japanese approach to improving mathematics teaching and learning. Mahwah, NJ: Lawrence Erlbaum.

Freudenthal, H. (1983). Didactical phenomenology of mathematical structures. Dordrecht: Reidel.

Frobisher, L., \& Threlfall, J. (1999). Teaching and assessing patterns in number in the primary years. In A. Orton (Ed.), Pattern in the teaching and learning of mathematics (pp. 84-103). London: Cassell.

Glade, M., \& Prediger, S. (2017). Students' individual schematization pathways-Empirical reconstructions for the case of part-of-part determination for fractions. Educational Studies in Mathematics, 94(2), 185-203.

Gravemeijer, K. (1994). Developing realistic mathematics education. Utrecht: CD- $\beta$ Press.

Gravemeijer, K. (1998). Developmental Research as a Research Method. In J. Kilpatrick \& A. Sierpinska (Eds.), What is research in mathematics education and what are its results? (pp. 277-295). Dordrecht: Kluwer.

Gravemeijer, K., \& Cobb, P. (2006). Design research from a learning design perspective. In J. V. D. Akker, K. Gravemeijer, S. McKenney, \& N. Nieveen (Eds.), Educational design research: The design, development and evaluation of programs, processes and products (pp. 17-51). London: Routledge.

Hußmann, S., \& Prediger, S. (2016). Specifying and structuring mathematical topics-A fourlevel approach for combining formal, semantic, concrete, and empirical levels exemplified for exponential growth. Journal für Mathematik-Didaktik, 37(Suppl. 1), 33-67.

Hußmann, S., Rezat, S., \& Sträßer, R. (2016). Subject matter didactics in mathematics education. Journal für Mathematik-Didaktik, 37(1), 1-9.

Hußmann, S., Thiele, J., Hinz, R., Prediger, S., \& Ralle, B. (2013). Gegenstandsorientierte Unterrichtsdesigns entwickeln und erforschen - Fachdidaktische Entwicklungsforschung im Dortmunder Modell [Developing and investigating topic specific instrucitonal designs]. In M. Komorek \& S. Prediger (Eds.), Der lange Weg zum Unterrichtsdesign [The long pathway to instrucitonal designs] (pp. 19-36). Münster al: Waxmann.

Kaput, J. (2008). What is algebra? What is algebraic reasoning? In J. Kaput, D. W. Carraher, \& M. L. Blanton (Eds.), Algebra in the early grades (pp. 5-17). New York: Routledge. 
Kelly, A. E. (2013). When is Design Research Appropriate? In T. Plomp \& N. Nieveen (Eds.), Educational design research-Part A: An introduction (pp. 135-147). Enschede: Netherlands Institute for Curriculum Development.

Kirsch, A. (1978). Aspects of simplification in mathematics teaching. In H. Athen \& H. Kunle (Eds.), Proceedings of the 3rd International Congress on Mathematical Education (pp. 98-120). Karlsruhe: FIZ.

KMK [Kultusministerkonferenz]. (2004). Bildungsstandards im Fach Mathematik für den Primarbereich [Standards in primary school mathematics]. Retrieved from http://www.kmk. org/fileadmin/Dateien/veroeffentlichungen_beschluesse/2004/2004_10_15-BildungsstandardsMathe-Primar.pdf.

Lesh, R., \& Sriraman, B. (2005). Mathematics education as a design science. ZDM Mathematics Education, 37(6), 490-505.

Lewis, C., Perry, R., \& Murata, A. (2006). How should research contribute to instructional improvement? The case of lesson study. Educational Researcher, 35(39), 3-14.

Link, M. (2012). Grundschulkinder beschreiben operative Zahlenmuster [Children in primary school describe operative patterns of numbers]. Wiesbaden: Springer.

Mason, J. (2016). In conversation with John Mason-Laurinda Brown interviews John Mason, who directed the Centre for Mathematics Education at Open University. Mathematics Teaching, 254, $42-45$.

Morgan, C. (1998). Writing mathematically. The discourse of investigation. London: Falmer Press.

Morgan, C. (2001). The place of pupil writing in learning, teaching and assessing mathematics. In P. Gates (Ed.), Issues in mathematics teaching (pp. 232-244). London: Routledge.

Wittmann, E. Ch., \& Müller, G. N. (1990). Handbuch produktiver Rechenübungen [The handbook of productive exercises of calculating]. Stuttgart: Klett.

Wittmann, E. Ch., \& Müller, G. N. (2009). Das Zahlenbuch - Handbuch zur Frühförderung [The number book-Handbook of early support]. Stuttgart: Klett.

Wittmann, E. Ch., \& Müller, G. N. (2012). Das Zahlenbuch 1 - Begleitband [The number book 1 -Companion volume]. Stuttgart: Klett.

NAEYC \& NCTM. (2002/updated 2010). Early childhood mathematics: Promoting good beginnings. Retrieved from https://www.naeyc.org/files/naeyc/file/positions/psmath.pdf.

National Council of Teachers of Mathematics (NCTM). (2000). Principles and Standards for School Mathematics. Reston, VA: NCTM.

Nührenbörger, M., \& Schwarzkopf, R. (2016). Processes of mathematical reasoning of equations in primary mathematics lessons. In N. Vondrová (Ed.), Proceedings of the 9th Congress of the European Society for Research in Mathematics Education (CERME 9) (pp. 316-323). Prag: ERME.

Nührenbörger, M., \& Schwarzkopf, R. (2017) (Eds.). Das Zahlenbuch 2 [The numberbook 2]. Leipzig: Klett.

OECD. (2013). PISA 2015-Draft mathematics framework. Retrieved from https://www.oecd.org/ pisa/pisaproducts/Draft\%20PISA\%202015\%20Mathematics\%20Framework\%20.pdf.

Plomp, T. (2013). Educational design research: An introduction. In T. Plomp \& N. Nieveen (Eds.), Educational design research-Part A: An introduction (pp. 10-51). Enschede: Netherlands Institute for Curriculum Development.

Plomp, T., \& Nieveen, N. (2013). Educational design research. Enschede: SLO, Netherlands Institute for Curriculum Development.

Prediger, S., Leuders, T., \& Rösken-Winter, B. (2017). Drei-Tetraeder-Modell der gegenstandsbezogenen Professionalisierungsforschung: Fachspezifische Verknüpfung von Design und Forschung [The model of three tetrahedrons in the topic specific research of proressionalisation. The subject specific alliance of Design and Research]. Jahrbuch für Allgemeine Didaktik, 2017, 159-177.

Prediger, S., \& Zwetzschler, L. (2013). Topic-specific design research with a focus on learning processes: The case of understanding algebraic equivalence in grade 8. In T. Plomp \& N. Nieveen (Eds.), Educational design research: Illustrative cases (pp. 407-424). Enschede: SLO, Netherlands Institute for Curriculum Development. 
Rösken-Winter, B., \& Szczesny, M. (2016). Continuous professional development (CPD): Paying attention to requirements and conditions of innovations. In S. Doff \& R. Komoss (Eds.), Making change happen: Wandel im Fachunterricht analysieren und gestalten (pp. 129-140). Wiesbaden: Springer Fachbuch.

Ruthven, K., Laborde, C., Leach, J., \& Tiberghien, A. (2009). Design tools in didactical research: Instrumenting the epistemological and cognitive aspects of the design of teaching sequences. Educational Researcher, 38(5), 329-342.

Schwarzkopf, R., Nührenbörger, M., \& Mayer, C. (2018). Algebraic understanding of equalities in primary classes. In C. Kieran (Ed.), Early Algebra (pp. 195-212). Rotterdam: Springer.

Simon, H. A. (1970). The sciences of the artificial. Cambridge, MA: MIT Press.

Steinbring, H. (2005). The construction of new mathematical knowledge in classroom interaction. An epistemological perspective. Berlin: Springer.

Steinweg, A. S. (2004). Zahlen in Beziehungen - Muster erkennen, nutzen, erklären und erfinden [Numbers in relations-recognising, explaining and inventing patterns]. In P. Scherer \& D. Bönig (Eds.), Mathematik für Kinder-Mathematik von Kindern [Mathematics for children-mathematics of children] (pp. 232-242). Frankfurt a. M.: Grundschulverband - Arbeitskreis Grundschule e. V.

Steinweg, A. S. (2013). Algebra in der Grundschule [Algebra in primary schools]. Heidelberg: Springer Spektrum.

Steinweg, A. S. (2017). Key ideas as guiding principles to support algebraic thinking in German primary schools. In T. Dooley \& G. Gueudet (Eds.), Proceedings of the Tenth Congress of the European Society for Research in Mathematics Education (CERME10), February 1-5, 2017 (pp. 512-519). Dublin, Ireland: DCU Institute of Education and ERME.

Steinweg, A., Akinwunmi, K., \& Lenz, D. (2018). Making implicit algebraic thinking explicit: Exploiting national characteristics of German approaches. In C. Kieran (Ed.), Teaching and learning algebraic thinking with 5- to 12-year olds: The global evolution of an emerging field of research and practice (pp. 283-307). Cham: Springer International Publishing.

Treffers, A. (1987). Three dimensions. A model of goal and theory description in mathematics instruction. Dordrecht: Reidel.

Van den Akker, J., Gravemeijer, K., McKenney, S., \& Nieveen, N. (2006). Introducing educational design research. In J. van den Akker, K. Gravemeijer, S. McKenney, \& N. Nieveen (Eds.), educational design research (pp. 3-7). London: Routledge.

Vohns, A. (2016). Fundamental ideas as a guiding category in mathematics education: Early understandings, developments in german-speaking countries and relations to subject matter didactics. Journal für Mathematikdidaktik (JMD), (Suppl. 1), 193-223.

Vollrath, H.-J. (1978). Rettet die Ideen! [Save the ideas!]. MNU, 31(8), 449-455.

Whitehead, A. N. (1929). The aims of education and other essays. New York: Macmillan.

Winter, H. (1975). Allgemeine Lernziele für den Mathematikunterricht? [General educational objectives in teaching mathematics?]. ZDM, 3, 106-116.

Wittmann, E. Ch. (1974). Didaktik der Mathematik als Ingenieurwissenschaft [Mathematics education as engineering]. Zentralblatt für Didaktik der Mathematik, 6, 119-122.

Wittmann, E. Ch. (1995). Mathematics education as a "design science". Educational Studies in Mathematics 29, 355-374 [repr. In A. Sierpinská \& J. Kilpatrick (Eds.) (1998), Mathematics Education as a Research Domain. A Search for Identity (pp. 87-103). Dordrecht: Kluwer].

Wittmann, E. Ch. (2001a). Developing mathematics education in a systemic process. Educational Studies in Mathematics, 48(1), 1-20.

Wittmann, E. Ch. (2001b). Drawing on the richness of elementary mathematics in designing substantial learning environments. In M. van den Heuvel-Panhuizen (Ed.), Proceedings of the 25th Conference of PME (Vol. 1, pp. 193-197), Utrecht, The Netherlands.

Wittmann, E. Ch. (2015). Structure-genetic didactical analyses-Empirical research "of the first kind". In P. Błaszczyk, B. Pieronkiewicz, \& M. Samborska (Eds.), Mathematical transgressions (pp. 5-19). Kraków: PWN. 
Wittmann, E. Ch. (2016). Collective teaching experiments: Organizing a systemic cooperation between reflective researchers and reflective teachers in mathematics education. In M. Nührenbörger, B. Rösken-Winter, C. I. Fung, R. Schwarzkopf, E. Wittmann, K. Akinwunmi, et al. (Eds.), Design science and its importance in the German mathematics educational discussion (pp. 22-29). Rotterdam: Springer.

Open Access This chapter is licensed under the terms of the Creative Commons Attribution 4.0 International License (http://creativecommons.org/licenses/by/4.0/), which permits use, sharing, adaptation, distribution and reproduction in any medium or format, as long as you give appropriate credit to the original author(s) and the source, provide a link to the Creative Commons licence and indicate if changes were made.

The images or other third party material in this chapter are included in the chapter's Creative Commons licence, unless indicated otherwise in a credit line to the material. If material is not included in the chapter's Creative Commons licence and your intended use is not permitted by statutory regulation or exceeds the permitted use, you will need to obtain permission directly from the copyright holder. 